\title{
Design and performance evaluation of a novel end-effector with integrated gripper cum cutter for harvesting greenhouse produce
}

\author{
Nilesh R. Kolhalkar ${ }^{1,2^{*}}$, V. L. Krishnan ${ }^{3}$, Anupama A. Pandit ${ }^{4}$, R.G. Somkuwar ${ }^{5}$ and Jahier A. Shaaikh ${ }^{6}$ \\ Research scholar, Department of Mechanical Engineering, Koneru Lakshmaiah Education Foundation, \\ Vaddeswaram, Guntur-02, A.P., India ${ }^{1}$ \\ Assistant Professor, Department of Mechanical Engineering, MKSSS's C.C.O.E.W, Pune, India ${ }^{2}$ \\ Associate Professor, Department of Mechanical Engineering, V. R. Siddhartha Engineering College, Vijayawada, \\ A.P, India ${ }^{3}$ \\ Research scholar, Department of Computer Science and Engineering, Defence Institute of Advanced Technology \\ (DIAT), DRDO, Pune-25, MH, India ${ }^{4}$ \\ Director (Acting) and Principal Scientist, ICAR-National Research Centre for Grapes (NRCG), Pune-07, MH.India ${ }^{5}$ \\ Lecturer, Department of Mechanical Engineering, Debre Tabor University, South Gonder, Ethiopia ${ }^{6}$
}

Received: 28-July-2021; Revised: 16-November-2021; Accepted: 19-November-2021

(C)2021 Nilesh R. Kolhalkar et al. This is an open access article distributed under the Creative Commons Attribution (CC BY) License, which permits unrestricted use, distribution, and reproduction in any medium, provided the original work is properly cited.

\begin{abstract}
Motivation for current work is to reduce the harvesting cost and increase the shelf life of the post-harvested yield of grapes and greenhouse produce using harvesting robots. A novel end-effector design comprising of cutter integrated with a gripper is developed, tested, and validated for harvesting different types of Greenhouse produce. For evaluating the efficacy of the novel end-effector, experiments are carried out on various vegetables and fruits like Table Grapes, Sweet Bell Pepper, Bitter Melon, Long Hot Chili Pepper, Eggplant, and Okra with average harvesting time of 28, 19, 17, 20, 17 and 18 seconds respectively. The designed novel end-effector viz. gripper cum cutter is compact in size and lightweight. It is attached to a custom-built pneumatically operated robotic arm, mounted on a multi-purpose agricultural vehicle. Once the fruit is detected through image sensing, a mechatronic module activates the gripper first to firmly grasp the peduncle of fruit, and the cutter cuts it, without any physical contact with fruit, resulting in the increased shelf life of fruit. The harvesting module is capable of harvesting various fruits and vegetables with an effective field capacity of 4.625 ha/hr with an effective operating time of 9.25 hrs in a 10 hours of a day with a field efficiency of $92.5 \%$.
\end{abstract}

\section{Keywords}

Design thinking, Fruit harvesting, Mechatronics, Smart farming, Precision agriculture.

\section{Introduction}

Precision Agriculture (PA) is now a day's buzzword used for the implementation of Mechatronics, Robotics, and Artificial Intelligence in various agricultural and allied tasks [1]. These robots are highly complex with different subsystems, which need to be integrated. This integration is possible using the Design Thinking approach. Mechatronics design of such a system mainly includes a synergetic amalgamation of different disciplines of engineering like Mechanical, Electronics, Computer, IT, and intelligent control systems.

\section{*Author for correspondence}

This work was supported in part by Assistance by S.P.P.U for Project-based Innovative Research (ASPIRE) with Research Grant No. 18TEC000968, Pune, India in collaboration with I.C.A.R, National Research Center for Grapes (N.R.C.G.) Pune.

1479
Fruit harvesting is a very labor-intensive task that needs to be automated. Mechatronics modules for the various agricultural and allied tasks along with different types of fruits and vegetable harvesting robots working in the different agricultural environments have been developed in the last few decades [2-4]. Each year half the fruits, vegetables of the world produce are wasted with the reported loss in the range of $4.58 \%$ to $15.88 \%$. Major quality deterioration and loss occurred during the manual harvesting process of horticulture and greenhouse produce which is also a labor-intensive task. The conventional harvesting process in viticulture also results in damaging the thin waxy layer from the major export quality fruits like Table grapes, reducing the shelf life of the grapes. 
Motivation for this research work is to reduce the harvesting cost \& time for labor-intensive tasks with minimal fruit handling and to increase the shelf life of the harvested fruits and vegetables by using automation in Vertical Farming, Orchards, and Greenhouse. This will also provide the solution to the availability of skilled and semi-skilled labor and high labor cost [5]. Highly unstructured orchard environment, dynamic outdoor conditions, delicate products, wide variation in size, shape, and color of fruits and vegetables have made agricultural automation a very challenging task $[6,7]$. The research community has been engaged in harvesting robots for the last 25 years, but fruit harvesting robots have not yet been commercially available. The main reasons for failure in commercialization have been the slow operational speed of harvesting robots compared to their human counterpart, bulky design, and complex control technology, etc. [8]. All the fruits and vegetables are harvested by grasping the fruit in hand and then either rotating the peduncle, pulling the peduncle, or cutting it using scissors [9, 10]. During this process, the thin waxy protective layer from the fruit surface is gets damaged resulting in the shorter lifecycle or spoilage of the fruit. Design Thinking methodology is used in the current work that breaks the conventional design approach by emphasizing solutions and innovations over the tradition[11]. The prime objective of the current research work is to propose a novel method of fruit grasping by holding the fruit at its peduncle or stem without making any physical contact with the fruit surface by implementing low-cost innovation in traditional farming, optimizing the post-harvest loss in the food production process and improve the quality of the farm produce with minimal human intervention. However, the speed of the proposed robotic harvesting is still less than that of human harvesting due to the multitasking skills of human beings that cannot be matched by any modern control system.

\section{Literature review}

Harvesting robots for various fruit and vegetables like Cucumber, Apple, Strawberry, Cherry, Tomato, Saffron, Citrus, Mushroom, etc. have been studied [12-18]. Selective Robotic harvesting is implemented for selective fruits and high-value crops that help farmers to overcome the problem of paucity of skilled labor, reduction in the labor cost with improved quality yield [19].

In a natural environment, fruit identification and localization is a very challenging task as most fruits are occluded by leaves and branches, partially or fully or overlapped with other fruits [20].

Many digital technologies are implemented in modern viticulture like GPS, GIS, AI, and Decision Support Systems. Computer vision is effective as a primary sensory system for horticultural applications [21]. Different plant training systems have been investigated for effective robotic harvesting [22]. State-of-the-art robotic grippers, grasping capabilities and different control strategies are developed for robotic harvesting [23, 24]. Automatic grading of strawberry adds a closed image box to capture the images under the same light intensity for harvesting [25]. Manipulator regulated by the control system for automatic harvesting with a vision-based system for detection and localization of the apple in the trees has been tested and results presented [26]. Autonomous Saffron harvesting robot based on the saffron plants locations and dimensions tested satisfactorily due to the delicate nature of the flower [27]. The stereo vision system which provides control of the actions to be performed by the robotic arm is attached to the end effector [28]. The modularity of robotic arms to perform different types of agricultural tasks has yielded encouraging outcomes [29]. Gripper for strawberry harvesting with measurements of maximum gripping force under the variety of picking techniques has been studied [30]. Multipurpose agriculture vehicle with mechatronics module for harvesting in orchards and pesticide spraying has been designed, developed and validated at I.C.A.R, National Research Center for Grapes (ICAR-NRCG), Pune. Post-harvest loss ranging from $20 \%$ to $50 \%$ was reported in various phases from the farm till it is get consumed [31, 32]. Various harvesting technologies have been reported for harvesting the variety of the Chinese fruits [33]. Very few robotic fruit harvesting systems are commercialized from last few decades and widespread use of harvesting robots in orchards is yet to be seen [34].

All the reported work-related to robotic fruit harvesting includes the physical contact with the fruit surface, affecting the quality of the harvested fruit. The contribution of the current work provides the solution to reduce the post-harvest loss and improve the fruit grasping capability with minimum human interference which is achieved by holding the fruit at the peduncle or stem instead of grasping it around its surface. Uniquely designed and developed gripper cum cutter is fixed to the end-effector, which is mounted on a custom-built agricultural vehicle with various mechatronic modules. The vehicle has been 
deployed for harvesting various Greenhouse produce especially Grapes in addition to Sweet Bell Pepper, Bitter Melon, Hot long chili pepper, Eggplant, and Okra (Lady Finger), etc. The efficacy of the harvesting system has been also reported in this paper along with a few performance parameters.

\section{Methods}

\subsection{Design of the novel end-effector}

In general, various fruits and vegetables are grown in orchards and greenhouse environments are harvested manually using different types of pruners and Scissors (Figure 1(a)). However, conventional manual harvesting is a monotonous task and required skilled labor. However, the availability of skilled laborers, high labor costs, high energy input during the harvesting period, and low return on investment are major problems faced by Indian farmers. Invariably, Grapes in the vineyards and other greenhouse produce get spoiled on the plant itself due to the non-availability of skilled laborers during harvesting season. The disadvantage of manual harvesting is that a naturally developed thin protective waxy layer on the external surface of the grape berry gets damaged due to wrong handling during harvesting (Figure $1(b)$ ), resulting in the reduction of shelf life of the produce.

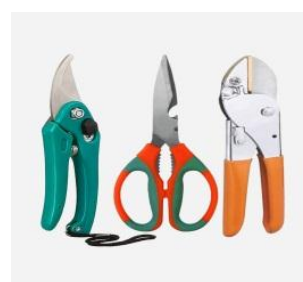

(a)

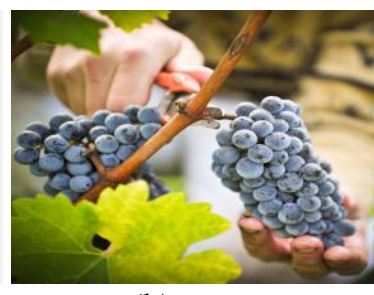

(b)
Figure 1 a) Pruners tool b) Conventional harvesting

Hence, the task of harvesting fruits and vegetables in orchards and greenhouses needs to be automated. A design thinking approach has been implemented to find the solution to the defined problem. For harvesting the grapes successfully, the harvesting system needs to fulfill the following requirements.

- Proper navigation of the agricultural vehicle (carrying the necessary harvesting robot) within the rows of vineyards or greenhouses.

- Identification of the fruit and its peduncle

- The approach of manipulator towards the fruit

- Gripping and cutting fruit from the peduncle.

In vertical farming and greenhouse of modern orchards, tree branches are trained along the trellis wires and a few other orchard parameters like branch spacing, no. of the plant along vertical directions are relatively structured, which is an advantage for implementing the proposed robotic fruit harvesting system. Other than the harvesting period, the proposed model can perform various allied agricultural tasks like weed management and major disease detection, diagnosis, and control. The authors have reported the satisfactory performance of all such allied tasks.

\subsection{Methodology of the novel end-effector}

In the process of harvesting fruits and vegetables from the plants or trees using conventional scissors and pruners, the fruits and vegetables fall due to gravity, leading to damage in the yield and spoilage of fruits. Major quality deterioration and post-harvest loss of many horticultural crops have been reported in the last decade [15]. Hence, there exists a need to firmly hold the bunch of fruits and/ or vegetables in hands, to prevent them from falling due to gravity while harvesting. In addition to the above-mentioned aspect, yet another important challenge in the harvesting of grapes lies in preserving the thin and fine waxy coating (widely known as "bloom") on the berry surface. If the bloom on the berry surface gets erased while harvesting, it leads to the rapid loss of water through the skin of the berries and the grapes will shrivel during the post-harvesting storage, resulting in the shorter shelf life of the grapes clusters.

The design thinking approach offers a structured framework for understanding and pursuing problemsolving in ways that contribute to the growth and add real value to the users (Figure 2). Designers have many creative approaches and tools to study problems, devise imaginative solutions, and find the best path forward. Design thinking follows a similar process for creative and innovative problem-solving rather than a set formula for results [11].

Hence to obtain a good quality yield of grapes, a design thinking approach has been adopted. To address the challenge of harvesting, various designs of Scissors, Pruners used for cutting operations and various designs of Pliers, Clippers (Figure 3), available in the market are used for gripping operations were studied. Inputs have been collected from the local farmers and suggestions are taken from the senior scientists and field supervisor of the Indian Council for Agricultural Research (I.C.A.R) National Research Center for Grapes (NRCG, Pune) to develop a suitable Mechatronics system to 
implement automated harvesting of grapes and good agricultural practices in viticulture. The proposed solution has been tested and validated successfully in Grapes farm at NRCG, Pune. Based on the design thinking approach and associated efforts, a novel design of gripper cum cutter (an integrated mechanism) was conceived to automate the harvesting process to prevent damage to the bloom on the berry surface. The novel end effector has been designed to first grasp the bunch of grapes at an appropriate location viz. peduncle and then detach it using the sharp cutting edge of the cutter. Figure 3 shows a wire cutter placed on nose pliers to simulate the integration of gripper and cutter. Figure 4(a) shows the solid modeling of the proposed integrated gripper and Figure $4(b)$ shows the actual testing and validation of the conceived end-effector during lab trials.

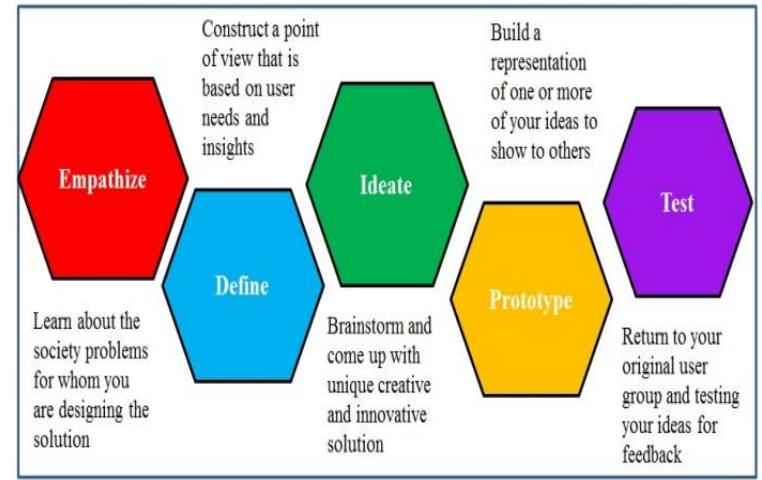

Figure 2 Design thinking methodology

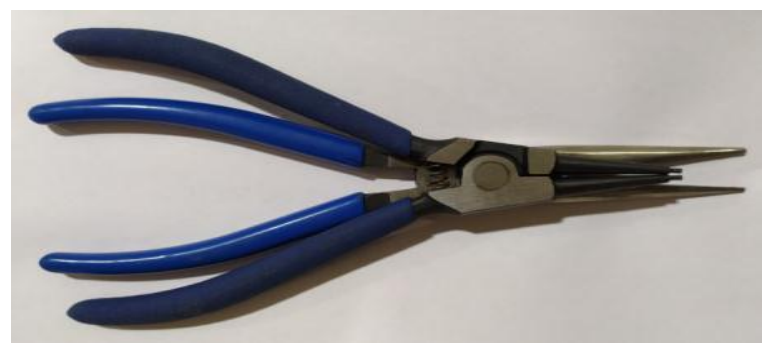

Figure 3 Wirecutter placed on the Nose plier

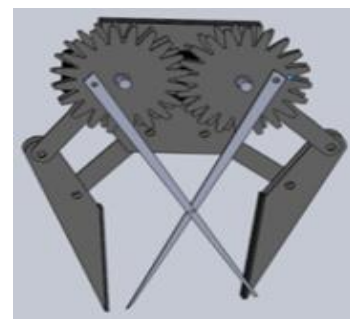

(a)

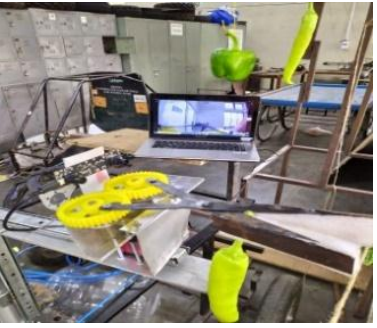

(b)
Figure 4 a) Solid Model of the integrated endeffector. b) Testing of the integrated end-effector 1482
3.3Calculation of cutting and gripping force Gripping and cutting are the two important operations to be performed while harvesting any type of fruit. The patented design of the proposed novel integrated gripper first grasps the peduncle of any fruit that is to be harvested and then the cutter detached it from the plant. Figure 5(a) shows the free body diagram (FBD) for calculating the cutting forces and Figure $5(b)$. shows the experimental setup for calculating cutting forces required for cutting a peduncle in which known standard weights were added in an empty pan to find out the force at which the peduncle of grapes bunch will be get cut using scissor. To accomplish automated harvesting while fulfilling the relevant constraints, a servo motor capable of generating required torque through the conceived end-effector (i.e. gripper cum cutter) need to be identified.

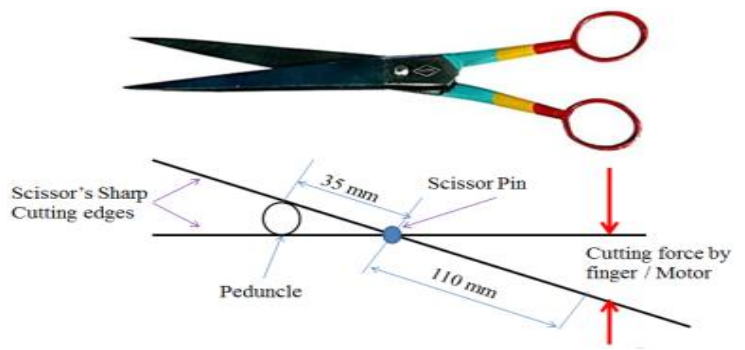

(a)

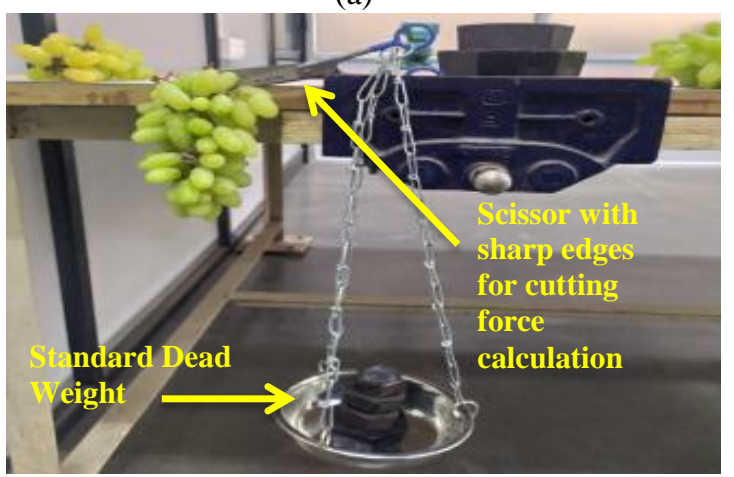

(b)

Figure 5 a) FBD of the cutter b) Experimental setup for evaluating the End-effector parameters

To determine the appropriate cutting force to be applied at the peduncle which connects a bunch of grapes to the branches of grape trees, the following methodology has been adopted. Initially, tests were performed on a sample bunch of grapes in a laboratory, using the novel end-effector equipped with the scissor. Weights were added to the pan to find out the optimum force required to cut any particular fruit peduncle. The minimum weight added in the pan with which the scissor cuts the peduncle of 
the particular sample gives the optimum cutting force required for that fruit. After testing 30 such samples for different types of fruits and vegetables, the minimum force required to cut the peduncle has been obtained as $30 \mathrm{~N}$ and maximum force as $35 \mathrm{~N}$. The average cutting force $(\mathrm{Fc})$ was found to be $31.55 \pm$ $8.90 \mathrm{~N}$ for various types of fruits and vegetables. This average cutting force is applied by holding the scissor's holding point between the thumb and middle finger of the right hand. The cutting force applied at the peduncle by the farmer while harvesting a bunch of grapes is measured using a strain gauge-based force sensor. For the automated counterpart of the manual operation, the cutting force has to be generated by a high torque servo motor. A servo motor capable of generating a maximum torque of $40 \mathrm{~kg}-\mathrm{cm}$ has been selected that can produce the cutting force of $35 \mathrm{~N}$, as required during harvesting at the peduncle. According to the free body diagram of the integrated cutter and gripper (Figure 5(a)), the actual cutting force acting at the cutting point of the peduncle is calculated as Equation 1,

$F C=(110 \times P) / 35=(110 \times 30) / 35=94.28 N(1)$

Equation (1) is used to calculate the cutting force $(\mathrm{Fc})$ applied by a scissor. The cutting force can be also improved by selecting a motor of even higher torque or by selecting larger scissors (i.e. by increasing the leverage). However, due to the constraint of space available for accessing the peduncle of a bunch of grapes amidst the branches of a tree, the option of the larger size of scissors is limited.

Equation (2) is used to calculate the gripping force $(\mathrm{Fg})$ required for grasping the peduncle or stem of any fruit. The types of the jaw used for robotic gripping applications are Friction or Encompassing type. Friction grip jaws depend on the force of the gripper to hold the peduncle. Encompassing jaws add stability and power by cradling the peduncle. The weight of the fruit or cluster (part) must be multiplied by a number of Gs (Earth Gravity $=1 \mathrm{G}$ ) to size the gripper. Following are the preferred values.

Friction Grip Jaw Factor $=4$

Encompassing Grip Jaw Factor $=1$

$1 \mathrm{G}=9.75$ meters $/ \mathrm{sec}^{2}$

Average grapes bunch weight $=450$ grams approx.

Total Grip force required for grasping the peduncle as shown in Equation 2.

$F g=$ Fruit wt. $\times(1+$ Part Gs $) \times J a w$ Factor
For Friction grip, $0.450 \mathrm{~kg}$ mass of fruit, $1.5 \mathrm{G}$ acceleration from robotic arm Equation 2 becomes, $F g=0.450 \times(1+1.5) \times 4=4.5 \mathrm{Kg}$ For Encompassing grip, $0.450 \mathrm{~kg}$ mass of fruit, 1.5G acceleration from robotic arm Equation 2 becomes, $F g=0.450 \times(1+1.5) \times 1=1.125 \mathrm{Kg}$

To verify the performance and demonstrate the effectiveness of the designed novel end-effector (i.e. Gripper cum Cutter) attached to the robotic manipulator, tests were conducted in the laboratory as well as in grapes orchards at NRCG, Pune. Various types of fruits and vegetables that can grow in a Greenhouse environment were used during these tests. Six different types of fruits and vegetables like Grapes, Sweet Bell Peppers, Bitter Melon, Long Hot Chili Peppers, Eggplant, and Okra (Lady Fingers) were selected for the experiments. The tests were conducted at the National Research Center for Grapes (ICAR-NRCG, Pune) under the supervision of senior scientists and with the assistance of field supervisors. (Figure 6)

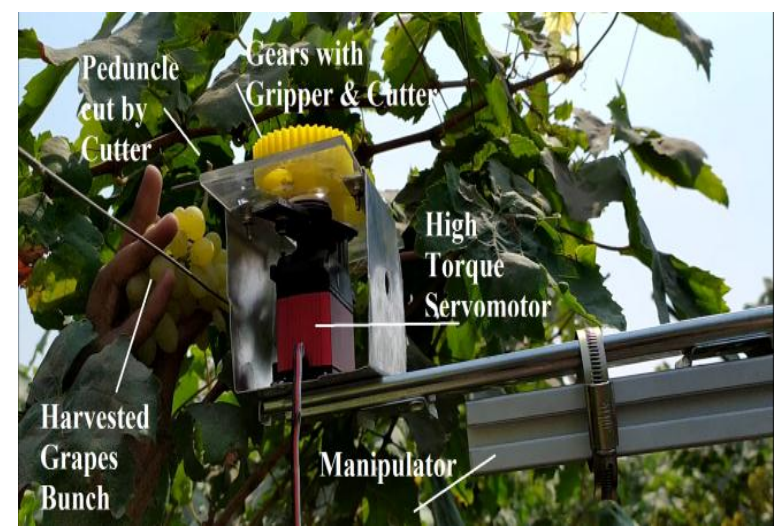

Figure 6 Testing of integrated gripper \& cutter during grapes harvesting at NRCG, Pune

During the experimentation work, two sets of tests were performed. In the first set of tests, greenhouse produce was placed on the table and the human operator/ farmer operates the end-effector manually to simulate the harvesting environment in a greenhouse and to approximately judge the amount of force required at the sharp cutting edges of the cutter (Figure $5(b)$ ). Also, it has been ensured that all the fruits and vegetables were held properly by the gripper at the peduncle between the gripping edges of the gripper. During this testing, it is observed that the fruits and vegetables do not fall down due to the gravity effect, which ensures the success of the gripping and cutting mechanism. 
In the second set of tests, the robotic manipulator equipped with the novel end-effector i.e. gripper cum cutter is deployed for harvesting. For harvesting grapes, detection of the peduncle is very important. The stereovision camera mounted near the end effecter of the harvesting manipulator, ensures that the peduncle is held between the gripping notches of the gripper and cutter. A Human-Machine Interface (HMI) is placed in front of the operator of the agricultural vehicle, on which the correct position of holding the peduncle of the fruit can be seen by the operator, as presented in Figure 7.

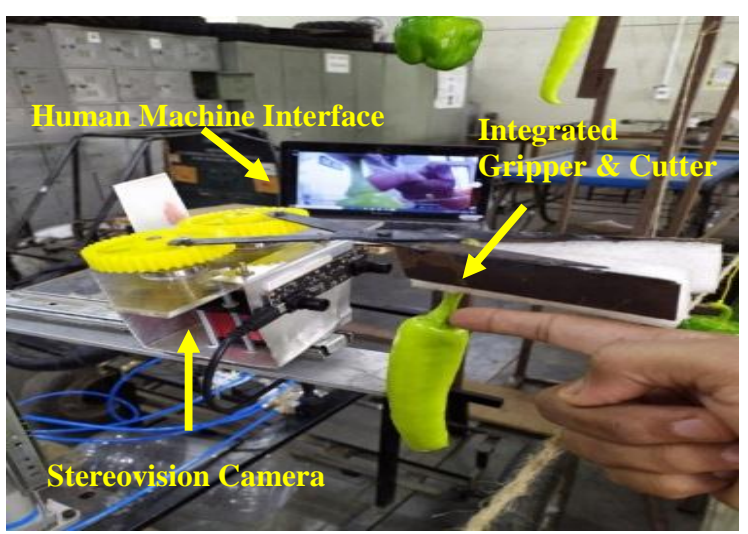

Figure 7 Mechatronic Module for Peduncle detection and gripper cum cutter for harvesting the fruit[35]

Once the operator ensures that the peduncle is within the cutting range of the cutter, then the operator gives a signal to the high torque servo motor to cut the fruit and detach it from the plant. During the cutting operation, a high torque servo motor rotates in a clockwise direction and for releasing the fruit, it rotates in an anticlockwise direction.

To design an appropriate end-effector for harvesting the fruits or vegetables, it is essential to measure the physical properties of the unit (bunch or single piece) being harvested from the respective trees/ plants. Physical properties of fruits and vegetables help to select appropriate sized DC motor so that required gripping and cutting force can be generated, during the harvesting process.

Tables 1 to 6 presents the maximum, minimum, and mean values of relevant physical properties of six different types of fruits and vegetables selected as a part of the experimental work. Physical properties chosen for measurement are main stem diameter, peduncle diameter, fruit or berry diameter, fruit height, and unit weight. Figure 8 shows the techniques adopted for the measurement of physical properties.
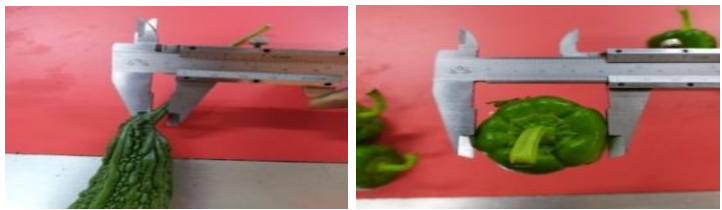

Figure 8 Measurements of physical properties

Table 1 Physical property of table grapes during testing (Value after \pm is Standard Deviation)

\begin{tabular}{lllll}
\hline Parameters & & Max. & Min. & Avg. \pm S.D \\
\hline $\begin{array}{l}\text { Main stem diameter } \\
{[\mathrm{mm}]}\end{array}$ & 12.25 & 10.50 & $11.57 \pm 0.68$ \\
\hline $\begin{array}{l}\text { Peduncle diameter } \\
{[\mathrm{mm}]}\end{array}$ & 6.35 & 4.90 & $5.51 \pm 0.590$ \\
\hline $\begin{array}{l}\text { Fruit berry } \\
{[\mathrm{mm}]}\end{array}$ & diameter & 22 & 19 & $20.8 \pm 1.303$ \\
\hline Bunch Height [mm] & 175 & 140 & $156.4 \pm 14.046$ \\
\hline Weight $[\mathrm{Kg}]$ & 0.845 & 0.335 & $0.663 \pm 0.2066$ \\
\hline Harvesting time [Sec] & 29 & 27 & 28 \\
\hline
\end{tabular}

Table 2 Physical properties of sweet bell pepper

\begin{tabular}{llll}
\hline Parameters & Max. & Min. & Avg. \pm S.D \\
\hline $\begin{array}{l}\text { Main stem diameter } \\
{[\mathrm{mm}]}\end{array}$ & 9.65 & 7.45 & $8.65 \pm 0.880$ \\
\hline $\begin{array}{l}\text { Peduncle diameter } \\
{[\mathrm{mm}]}\end{array}$ & 8 & 5.65 & $6.77 \pm 1.094$ \\
\hline Fruit diameter $[\mathrm{mm}]$ & 45 & 58 & $52.2 \pm 5.263$ \\
\hline Fruit height $[\mathrm{mm}]$ & 39 & 63 & $53 \pm 9.513$ \\
\hline Weight $[\mathrm{Kg}]$ & 0.357 & 0.28 & $0.304 \pm 0.030$ \\
\hline Harvesting time $[\mathrm{Sec}]$ & 20 & 18 & 19 \\
\hline
\end{tabular}

Compared to the orchards, nurturing environment of a plant and the working environment of the robotized harvesting system are structured in the greenhouse. Position of a plant, the distance between the plants, height of fruits and vegetables from the ground level, and orientation of the fruits, are a few of the parameters that are controllable in a greenhouse environment. Also, the illumination level is easy to control and the ground level is more regular than the actual field, which reduces the complexity in the design of the vehicle platform on which the harvesting system is mounted. Hence such a constrained environment of Greenhouse is apt for the robotic harvesting operations.

A major consideration concerning the robotic manipulator system mounted on the agricultural vehicle has been to adjust the harvesting system as per the height and orientation of the fruits and vegetables in the greenhouse. Also, fruits/ vegetables 
may be distributed all around the plant. To pick the fruits and vegetables which are at different heights and at different locations on the tree, the robotic manipulator system is mounted on the vehicle platform. It mainly consists of arms driven through two pneumatic cylinders. In vertical farming, the fruits and vegetables are grown at different heights above the ground level. The pneumatically actuated robotic arm mounted on the agricultural vehicle addresses the need of harvesting fruits/ vegetables at different heights from the ground level. The height of Grapes clusters during the harvesting period is from 3 feet to 6 feet above the ground level. For Bell Pepper, Eggplant, Hot chili pepper, Tomatoes, etc. this height is up to 3 feet. Hence for such a vertical farming applications, the height of the vehicle is kept up to 3 feet and then Manipulator is mounted on it, which can have a further reach of 3 feet for harvesting the fruits/ vegetables which can grow up to 6 feet above the ground level. The pneumatically actuated robotic manipulator enables the end-effector to access the appropriate fruit/ vegetable locations to grasp the fruit firmly and cut it at the peduncle. The entire system operates based on the feedback from the vision camera. To detect the presence of any fruit within the claws or jaws of the end-effector, a vision sensor is mounted near the end-effector, which accurately displays the position of the peduncle or stem of any type of fruit where the cutting edges should make the contact. Based on the vision sensor feedback at the HMI, the operator triggers the high torque servomotor to cut the peduncle by rotating the gears in a clockwise direction. These high torque servo motors are capable of producing a torque up to $40 \mathrm{~kg}-\mathrm{cm}$ which is just sufficient to cut the peduncle of any type of fruits/ vegetables having a peduncle diameter up to $15 \mathrm{~mm}$. Once the fruit or vegetable is detached from the peduncle, the gripper holds the fruit/ vegetable firmly. The manipulator then moves back to keep the detached fruits or vegetables in the storage containers. The high torque servomotor now rotates in an anticlockwise direction to release the firmly held fruit in a container, without causing any physical damage to the farm produce. The maximum and minimum harvesting time for all tested fruits and vegetables is from 35 seconds to 19 seconds.

Table 3 Physical properties of bitter melon

\begin{tabular}{llll}
\hline Parameters & Max. & Min. & Avg. \pm S.D \\
\hline $\begin{array}{l}\text { Main stem diameter } \\
{[\mathrm{mm}]}\end{array}$ & 8.35 & 7.85 & $8.01 \pm 0.204$ \\
\hline Peduncle diameter $[\mathrm{mm}]$ & 6.6 & 4.1 & $5.45 \pm 1.245$ \\
\hline Fruit diameter[mm] & 58 & 46 & $52.8 \pm 5.069$ \\
\hline Fruit height $[\mathrm{mm}]$ & 250 & 215 & $235.6 \pm 14.39$ \\
\hline
\end{tabular}

\begin{tabular}{llll}
\hline Parameters & Max. & Min. & Avg. \pm S.D \\
\hline Weight $[\mathrm{Kg}]$ & 0.144 & 0.114 & $0.132 \pm 0.011$ \\
\hline Harvesting time $[\mathrm{Sec}]$ & 18 & 16 & 17 \\
\hline
\end{tabular}

Table 4 Physical properties of long hot chili pepper

\begin{tabular}{lllll}
\hline \multicolumn{1}{l}{ Parameters } & Max. & Min. & Avg. \pm S.D \\
\hline $\begin{array}{l}\text { Main stem diameter } \\
{[\mathrm{mm}]}\end{array}$ & 6.15 & 5.5 & $5.9 \pm 0.2783$ \\
\hline $\begin{array}{l}\text { Peduncle diameter } \\
{[\mathrm{mm}]}\end{array}$ & 5.10 & 4.15 & $4.59 \pm 0.3990$ \\
\hline Fruit diameter $[\mathrm{mm}]$ & 37.4 & 33.35 & $35.65 \pm 1.617$ \\
& 5 & & \\
\hline Fruit height $[\mathrm{mm}]$ & 16.7 & 15.85 & $16.3 \pm 0.3872$ \\
& 5 & & \\
\hline Weight $[\mathrm{Kg}]$ & 0.04 & 0.034 & $0.0384 \pm 0.00$ \\
& 1 & 5 & 2 \\
\hline Harvesting Time [Sec] & 21 & 19 & 20 \\
\hline
\end{tabular}

Table 5 Physical properties of eggplant

\begin{tabular}{llll}
\hline Parameters & Max. & Min. & Avg. \pm S.D \\
\hline $\begin{array}{l}\text { Main stem diameter } \\
{[\mathrm{mm}]}\end{array}$ & 8.25 & 7.85 & $8.04 \pm 0.1673$ \\
\hline Peduncle diameter [mm] & 7.15 & 6.35 & $6.84 \pm 0.3361$ \\
\hline Fruit diameter [mm] & 78.15 & 65.85 & $71.72 \pm 4.6210$ \\
\hline Fruit height [mm] & 192 & 175 & $183.8 \pm 6.833$ \\
\hline Weight $[\mathrm{Kg}]$ & 0.418 & 0.378 & $0.393 \pm 0.0152$ \\
\hline Harvesting Time $[\mathrm{Sec}]$ & 18 & 16 & 17 \\
\hline
\end{tabular}

Table 6 Physical properties of Okra (Lady Finger)

\begin{tabular}{llll}
\hline Parameters & Max. & Min. & Avg. \pm S.D \\
\hline $\begin{array}{l}\text { Main stem diameter } \\
{[\mathrm{mm}]}\end{array}$ & 7.05 & 6.5 & $6.79 \pm 0.2219$ \\
$\begin{array}{l}\text { Peduncle diameter } \\
{[\mathrm{mm}]}\end{array}$ & 5.45 & 4.75 & $5.08 \pm 0.3033$ \\
\hline Fruit diameter $[\mathrm{mm}]$ & 19 & 23 & $21 \pm 1.5811$ \\
\hline Fruit height $[\mathrm{mm}]$ & 115 & 99 & $106.4 \pm 6.2289$ \\
\hline Weight $[\mathrm{Kg}]$ & 0.028 & 0.022 & $0.025 \pm 0.0023$ \\
\hline $\begin{array}{l}\text { Harvesting time } \\
{[\text { Sec] }}\end{array}$ & 19 & 17 & 18 \\
\hline
\end{tabular}

\section{Result}

Experimental results obtained after performing the field and laboratory testing demonstrated that the system can be successfully used for harvesting vegetables/ fruits such as Grapes, guava, tomatoes, bitter melon, sweet bell pepper, hot chili pepper, okra, eggplant, etc. with the maximum and minimum time of harvest as 34 seconds and 19 seconds respectively. The field trials are carried out at National Research Center for Grapes (ICAR-NRCG) with an average harvesting time of 28 seconds for each grapes cluster, without damaging the fruit. The performance of the proposed research work is 
evaluated and reported in Table 7 using the following key terms and their corresponding equations [36]

- Speed of Travel (S): It is the speed of the harvesting platform of an agricultural vehicle while it is moving within the rows of the vineyards or greenhouse, expressed in terms of Kilometer range it can cover in one hour. The vehicle is capable of moving at a speed of $5 \mathrm{Km} / \mathrm{hr}$.

- Operating Width (W): It is the rated width of the harvesting implement, expressed in meters (m) or in feet (ft)

- Theoretical Field Capacity $\left(\mathbf{T}_{\mathbf{f}}\right)$ : It is the rate of field coverage of an implement that would be obtained if the machine were performing its function $100 \%$ of the time at the rated forward speed and always covered $100 \%$ of its width. It is usually expressed in terms of hectares per hour (ha/hr). Equation 3 is the Theoretical Field Capacity $\left(\mathrm{T}_{\mathrm{f}}\right)$ in ha/hr.

- Effective Field Capacity $\left(\mathbf{C}_{\mathbf{f}}\right)$ : It is the actual average rate of coverage by the machine. It is expressed as ha/hr. Equation 5 is the Effective Field Capacity in ha/hr.

- Field Efficiency $\left(\mathbf{E}_{\mathbf{f}}\right)$ : It is the ratio of effective field capacity $\left(\mathrm{C}_{\mathrm{f}}\right)$ to theoretical field capacity $\left(\mathrm{T}_{\mathrm{f}}\right)$, in \%. It includes the effect of time lost in the field and failure to utilize the full width of the machine. Equation 4 is the Field Efficiency expressed in percentage $(\%)$.

Speed of Travel $(\mathrm{S})=5 \mathrm{Km} / \mathrm{hr}$

Operating Width $(\mathrm{W})=10$ meter

Theoretical Field Capacity $\left(\mathrm{T}_{\mathrm{f}}\right)=\frac{S \times W}{10}$

$=\frac{5 \times 10}{10}=5 \mathrm{ha} / \mathrm{hr}$

Assuming total loss time is $0.75 \mathrm{hrs}$. in a $10 \mathrm{hr}$. of day

$$
\begin{aligned}
\text { Field Efficiency }\left(\mathrm{E}_{\mathrm{f}}\right)=\frac{\text { output }}{\text { Input }} & \times 100 \\
=\frac{10-0.75}{10 \mathrm{hrs}} & \times 100=92.5 \% \\
\text { Effective Field Capacity }\left(\mathrm{C}_{\mathrm{f}}\right) & =\frac{S \times W \times E f}{10 \times 100} \\
& =\frac{5 \times 10 \times 0.925}{10}
\end{aligned}
$$

Table 7 Performance evaluation of proposed model

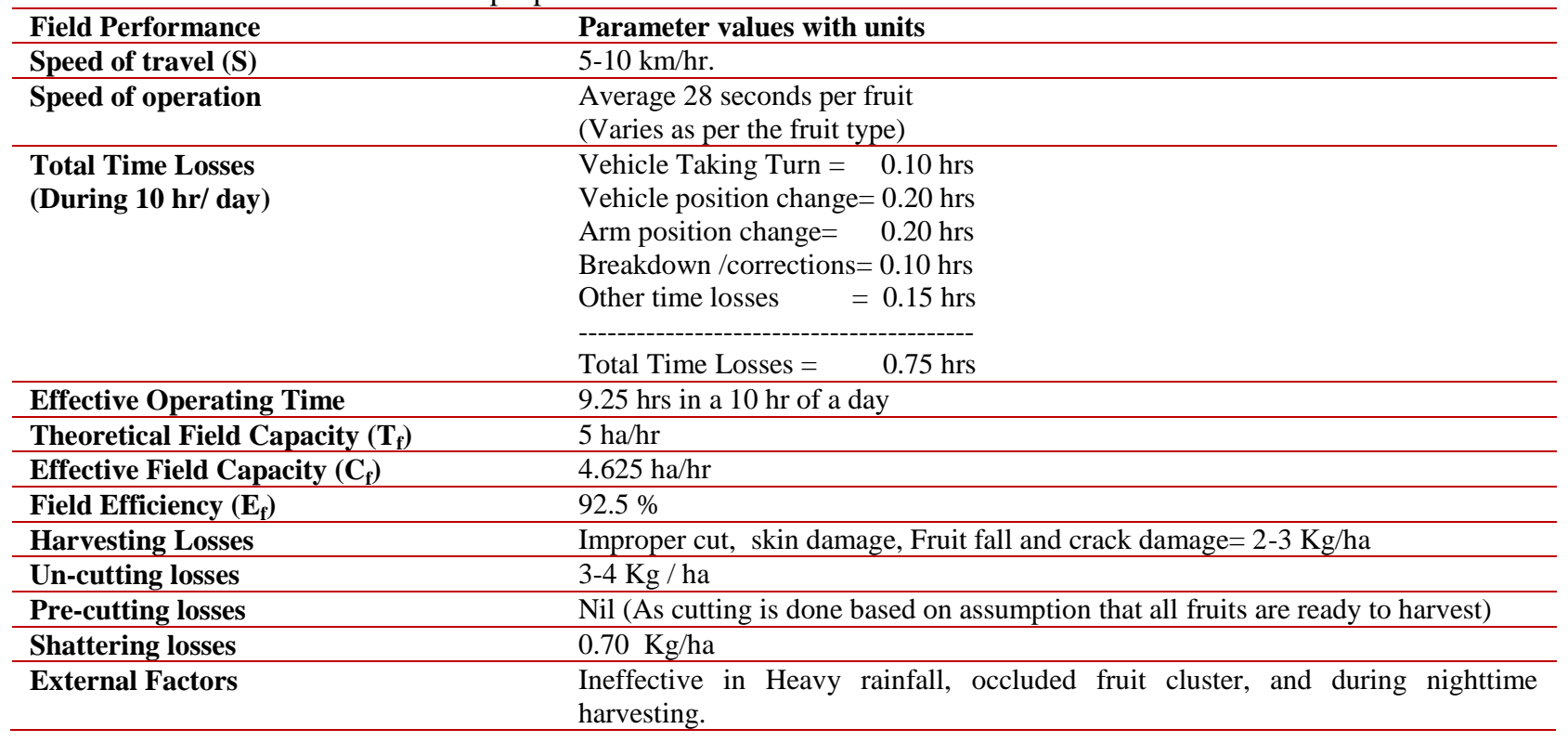

Effective/actual Field Capacity (Cf) is always less than the Theoretical Field Capacity (Tf) due to the time loss for some activity during operation.

This time loss includes adjusting and calibrating the electronic modules, breakdown, clogging, turning at ends, unloading harvested products, waiting for crop transport equipment, etc.

\section{Discussion}

The proposed research work is an implementation of a uniquely designed novel gripper cum cutter for harvesting various greenhouse produce and table 
grapes in vineyards. In earlier reported work all the robotic fruit harvesting methods were grasping the fruits and vegetables along the surfaces, resulting in the loss of shelf life of the fruit. In the proposed work, since there is no physical contact between the end-effector and the fruit surface during the harvesting process, the naturally occurring thin waxy layer of the bloom remains on the fruit for a longer period. Any hanging object has to fall on the ground due to the gravity effect, but in proposed research work, the gripper first holds the fruit at its stem or peduncle and then the cutter cuts the peduncle of the fruit to separate it from the plant, without making any physical contact with the fruit surface. Thus the proposed system leads to enhancement of the shelf life of the yield. However, the speed of harvesting still does not match with that of the conventional manual harvesting process, which is also the main reason for the non-commercialization of the fruit harvesting robots from the past few decades. The reported results are based on the harvesting of seasonal fruits and vegetables available in the market at the time of testing and experimentation work. The average harvesting time is 28 seconds for Table Grapes, 19 seconds for Sweet Bell Pepper,17 seconds for Bitter Melon,20 seconds for Long Hot Chili Pepper, 17 seconds for Eggplant, and 18 seconds for Okra. The maximum cutting force required for cutting the peduncle of any type of fruit is a maximum of 35 Newton. Hence the high torque servo motor, which is capable of producing the $40 \mathrm{~kg}-\mathrm{cm}$, is selected. As the proposed agricultural vehicle is developed for an off-road application, hence the maximum speed of travel is $5 \mathrm{~km} / \mathrm{hr}$. with which we have achieved a theoretical field capacity $\left(\mathrm{T}_{\mathrm{f}}\right)$ of 5 ha/hr., actual effective field capacity $\left(\mathrm{C}_{\mathrm{f}}\right)$ of 4.625 ha/hr., field efficiency $\left(\mathrm{E}_{\mathrm{f}}\right)$ of $92.5 \%$, assuming total loss time is $0.75 \mathrm{hrs}$. in a $10 \mathrm{hr}$. of the day. A complete list of abbreviations is shown in Appendix I.

\subsection{Limitations}

The proposed Mechatronic system of harvesting does not check the maturity level of ripeness of the fruits and complete the harvesting process based on the assumption that the proposed system is implemented during the harvesting period only. The limitation of the current design of the integrated gripper cum cutter is that it cannot be used to harvest heavy or large size massive fruits like pumpkins, jackfruit, papaya, watermelons, muskmelons, banana, pineapple, etc.
However, with some structural modifications in the current design of the fruits harvesting system these massive fruits and vegetables can be harvested which is also reported here as the scope of the current work.

\section{Conclusion and future work}

In this paper, a novel end-effector viz. gripper cum cutter has been designed, developed, tested, and validated for Table Grapes at National Research Center for Grapes (ICAR-NRCG) and for other fruits like Sweet Bell Pepper, Bitter Melon, Long Hot Chili Pepper, Eggplant and Okra in the orchards and greenhouse. Design thinking strategy has been implemented in the development of the harvesting system that helps to break the traditional design approach by accentuating solutions, innovations, creativity over tradition. The developed mechatronic module is small in size, simple in structure, light in weight, and economical. The novel gripper cum cutter simply first holds the fruit at its peduncle or stem and then the cutter cuts the peduncle to detach it from the plant. This robotic fruit harvesting method has reported minimal fruit surface contact with increasing shelf life of the harvested fruit. It can be easily mounted on a robot manipulator designed for relatively small payloads (say up to $3 \mathrm{~kg}$ ). Commercial implementation of harvesting robots for fruits and vegetables in vertical farming requires performance improvements in both robustness and speed. For most of the agricultural and allied tasks, farming robots have been reported as advantageous but, they are costlier, and being machines, they need a great deal of care and maintenance to keep them functioning. Due to many such reasons, fruit harvesting robots are not yet commercialized. Robotics in agriculture has reduced the dependency on human labor to the great extent. Research community has been working on improving the efficiency levels of such intelligent systems considerably with holistic farming approaches by application of emerging technologies like IoT, AI and ML, Data Science, Big data analytics.

\section{Acknowledgment}

This work is partially funded under the Assistance by Savitribai Phule Pune University for Project-based Innovative Research (ASPIRE) with Research Grant No. 18TEC000968, Pune, India in collaboration with I.C.A.R, National Research Center for Grapes (N.R.C.G.) Pune. This grant is utilized at MKSSS's Cummins College of Engineering for Women, Pune. 
Nilesh R. Kolhalkar et al.

Conflicts of interest

The authors have no conflicts of interest to declare.

\section{References}

[1] Murase H. Artificial intelligence in agriculture. Computers and Electronics in Agriculture. 2000; 29(1/2).

[2] Ringdahl O, Kurtser P, Edan Y. Evaluation of approach strategies for harvesting robots: case study of sweet pepper harvesting. Journal of Intelligent \& Robotic Systems. 2019; 95(1):149-64.

[3] Kolhalkar NR, Krishnan VL. Mechatronics system for diagnosis and treatment of major diseases in grape vineyards based on image processing. Materials Today: Proceedings. 2020; 23:549-56.

[4] Xiong Y, Ge Y, From PJ. An obstacle separation method for robotic picking of fruits in clusters. Computers and Electronics in Agriculture. 2020.

[5] Arikapudi R, Vougioukas SG. Robotic tree-fruit harvesting with telescoping arms: a study of linear fruit reachability under geometric constraints. IEEE Access. 2021; 9:17114-26.

[6] Lin G, Tang Y, Zou X, Li J, Xiong J. In-field citrus detection and localisation based on RGB-D image analysis. Biosystems Engineering. 2019; 186:34-44.

[7] Kolhalkar NR, Krishnan VL. Mechatronics system for diagnosis and treatment of major diseases in grape vineyards based on image processing. Materials Today: Proceedings. 2020; 23:549-56.

[8] Hohimer CJ, Wang H, Bhusal S, Miller J, Mo C, Karkee M. Design and field evaluation of a robotic apple harvesting system with a 3D-printed soft-robotic end-effector. Transactions of the ASABE. 2019; 62(2):405-14.

[9] Fan P, Yan B, Wang M, Lei X, Liu Z, Yang F. Threefinger grasp planning and experimental analysis of picking patterns for robotic apple harvesting. Computers and Electronics in Agriculture. 2021.

[10] Liu J, Peng Y, Faheem M. Experimental and theoretical analysis of fruit plucking patterns for robotic tomato harvesting. Computers and Electronics in Agriculture. 2020.

[11] https://www.simplilearn.com/benefits-of-designthinking-article. Accessed 24 October 2021.

[12] Monta M, Kondo N, Shibano Y. Agricultural robot in grape production system. In proceedings of international conference on robotics and automation 1995 (pp. 2504-9). IEEE.

[13] Joseph SP, Wijerathna LL, Epa KG, Egalla EK, Abeygunawardhana PW, De SR. Smart harvesting based on image processing. In international computer symposium 2020 (pp. 382-6). IEEE.

[14] Mao S, Li Y, Ma Y, Zhang B, Zhou J, Wang K. Automatic cucumber recognition algorithm for harvesting robots in the natural environment using deep learning and multi-feature fusion. Computers and Electronics in Agriculture. 2020.

[15] Bu L, Chen C, Hu G, Zhou J, Sugirbay A, Chen J. Assessment of apple damage caused by a flexible end- effector. INMATEH-Agricultural Engineering. 2020; 62(3):309-16.

[16] Xiong Y, Peng C, Grimstad L, From PJ, Isler V. Development and field evaluation of a strawberry harvesting robot with a cable-driven gripper. Computers and Electronics in Agriculture. 2019; 157:392-402.

[17] Li Z, Miao F, Yang Z, Wang H. An anthropometric study for the anthropomorphic design of tomatoharvesting robots. Computers and Electronics in Agriculture. 2019.

[18] Reed JN, Miles SJ, Butler J, Baldwin M, Noble R. AE-automation and emerging technologies: automatic mushroom harvester development. Journal of Agricultural Engineering Research. 2001; 78(1):15-23.

[19] Kootstra G, Wang X, Blok PM, Hemming J, Van HE. Selective harvesting robotics: current research, trends, and future directions. Current Robotics Reports. 2021; 2:95-104.

[20] Fu L, Gao F, Wu J, Li R, Karkee M, Zhang Q. Application of consumer RGB-D cameras for fruit detection and localization in field: a critical review. Computers and Electronics in Agriculture. 2020.

[21] Tardaguila J, Stoll M, Gutiérrez S, Proffitt T, Diago MP. Smart applications and digital technologies in viticulture: a review. Smart Agricultural Technology. 2021.

[22] Fountas S, Mylonas N, Malounas I, Rodias E, Hellmann SC, Pekkeriet E. Agricultural robotics for field operations. Sensors. 2020; 20(9):1-27.

[23] Zhang B, Xie Y, Zhou J, Wang K, Zhang Z. State-ofthe-art robotic grippers, grasping and control strategies, as well as their applications in agricultural robots: a review. Computers and Electronics in Agriculture. 2020.

[24] Zhang T, Huang Z, You W, Lin J, Tang X, Huang H. An autonomous fruit and vegetable harvester with a low-cost gripper using a 3D sensor. Sensors. 2020; 20(1):1-15.

[25] Feng Q, Chen J, Zhang M, Wang X. Design and test of harvesting robot for table-top cultivated strawberry. In WRC symposium on advanced robotics and automation 2019 (pp. 80-5). IEEE.

[26] Zhang K, Lammers K, Chu P, Li Z, Lu R. System design and control of an apple harvesting robot. Mechatronics. 2021.

[27] Mohanty NP, Singh D, Hota A, Kumar S. Cultivation of cash crops under automated greenhouse using internet of things (IoT). In international conference on communication and signal processing 2019 (pp. 2359). IEEE.

[28] Arad B, Balendonck J, Barth R, Ben-shahar O, Edan Y, Hellström T, et al. Development of a sweet pepper harvesting robot. Journal of Field Robotics. 2020; 37(6):1027-39.

[29] Fei Z, Vougioukas SG. Co-robotic harvest-aid platforms: real-time control of picker lift heights to maximize harvesting efficiency. Computers and Electronics in Agriculture. 2021. 
[30] Ge Y, Xiong Y, From PJ. Symmetry-based 3d shape completion for fruit localisation for harvesting robots. Biosystems Engineering. 2020; 197:188-202.

[31] Van HL, Kurtser P, Wittemans L, Edan Y. Crop design for improved robotic harvesting: a case study of sweet pepper harvesting. Biosystems Engineering. 2020; 192:294-308.

[32] Kasso M, Bekele A. Post-harvest loss and quality deterioration of horticultural crops in dire dawa region, Ethiopia. Journal of the Saudi Society of Agricultural Sciences. 2018; 17(1):88-96.

[33] Rysz MW, Mehta SS. A risk-averse optimization approach to human-robot collaboration in robotic fruit harvesting. Computers and Electronics in Agriculture. 2021.

[34] Zhou H, Wang X, Au W, Kang H, Chen C. Intelligent robots for fruit harvesting: recent developments and future challenges. Research Suare. 2021.

[35] https://ipindiaservices.gov.in/publicsearch. Accessed 24 October 2021.

[36] http://ecoursesonline.iasri.res.in/course/view.php?id=1 2. Accessed 24 October 2021.

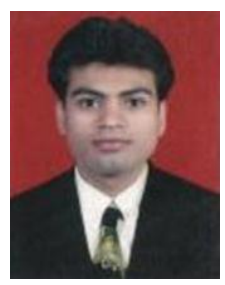

Nilesh R. Kolhalkar is a research scholar at K.L.E.F, Vaddeswaram, A.P, and working as Assistant Professor in the Mechanical Engineering Department of MKSSS's C.C.O.E.W, Pune. He has completed his Master's degree, M. Tech: Mechatronics from Government College of Engineering Pune (C.O.E.P). His research area includes Mechatronics, Robotics, Automotive Technology, Automation Control Technology, Agricultural Engineering, Precision Agriculture and E-Mobility.

Email: nrkolhalkar@rediffmail.com

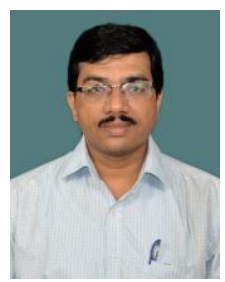

Dr. V. L. Krishnan is presently working at V.R. Siddhartha Engineering College, as Associate Professor. He has completed his Ph.D. from I.I.T Roorkee with a specialization in Robotics and Control. His research area includes Mechatronics System Design, Modeling and Control of Dynamic systems, Robotic Telemanipulation, Digital Manufacturing and Mechatronic Applications in Agriculture.

Email: krishnanv108@gmail.com

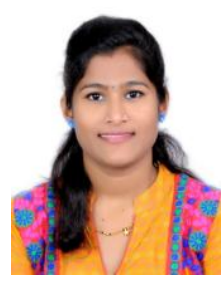

Anupama A. Pandit is currently a Research Scholar in the Department of Computer Science and Engineering, Defence Institute of Advanced Technology (D.I.A.T), DRDO, Pune. Her research area includes Mechatronics, IoT and Post-quantum Cryptography.

Email: anupamapandit91@gmail.com

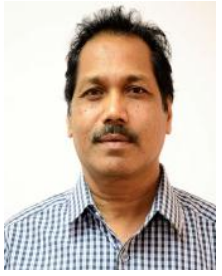

Dr. R. G. Somkuwar is currently a Director (Acting) and Principal Scientist at Indian Council for Agricultural Research (ICAR) National Research Centre for Grapes (NRCG), Pune. He has completed his Ph.D. in Horticulture from the Indian Agricultural Research Institute, New Delhi. His research area includes Canopy Management Practices in Wine and Table Grapes, Standardization of Cultural Practices in the Table and Wine Grapes, and Production of Quality Planting Material.

Email: director.nrcg@icar.gov.in

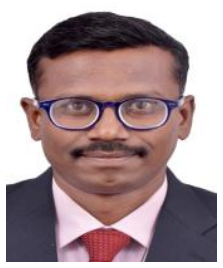

Jahier Abbas Shaaikh is a research scholar and working as a Lecturer in the Mechanical Engineering department at Debre Tabor University, Ethiopia. $\mathrm{He}$ is an Aerospace and Defence industry professional and engineering teacher with 20 years of experience. His research area includes Mechanical System Design and Automation.

Email: jahiershaikh9@gmail.com

\begin{tabular}{|c|c|c|}
\hline \multicolumn{3}{|c|}{ Appendix I } \\
\hline S. No. & Abbreviation & Description \\
\hline 1 & $\mathrm{AI}$ & Artificial Intelligence \\
\hline 2 & ASPIRE & Assistance by Savitribai Phule Pune \\
\hline & & $\begin{array}{l}\text { University for Project-based } \\
\text { Innovative Research }\end{array}$ \\
\hline 3 & $\mathrm{~cm}$ & centimeter \\
\hline 4 & FBD & Free Body Diagram \\
\hline 5 & $\mathrm{ft}$ & feet \\
\hline 6 & GIS & Geographic Information System \\
\hline 7 & GPS & Global Positioning System \\
\hline 8 & $\mathrm{Ha} / \mathrm{hr}$ & Hectares per hour \\
\hline 9 & HMI & Human Machine Interface \\
\hline 10 & hrs/day & hours per day \\
\hline 11 & I.C.A.R & $\begin{array}{l}\text { Indian Council of Agricultural } \\
\text { Research }\end{array}$ \\
\hline 12 & IoT & Internet of Things \\
\hline 13 & IT & Information Technology \\
\hline 14 & $\mathrm{Kg}$ & Kilogram \\
\hline 15 & $\mathrm{Kg} / \mathrm{hr}$ & Kilogram per hour \\
\hline 16 & $\mathrm{Km} / \mathrm{hr}$ & Kilometer per hour \\
\hline 17 & $\mathrm{~m}$ & meter \\
\hline 18 & ML & Machine Learning \\
\hline 19 & $\mathrm{~mm}$ & milimeter \\
\hline 20 & $\mathrm{~N}$ & Newton \\
\hline 21 & N.R.C.G & National Research Centre for Grapes \\
\hline 22 & PA & Precision Agriculture \\
\hline 23 & $\mathrm{sec}$ & seconds \\
\hline 24 & viz & Latin Videlicet \\
\hline
\end{tabular}

